\title{
OBITUARY
}

\section{AleXander Bruce RoXburgh}

THE death of Mr. Alexander Bruce Roxburgh, F.R.C.S., occurred on March 17, 1953, at his home at Locks Heath, Hants. Mr. Roxburgh studied at Exeter College, Oxford, and at the London Hospital, qualified in 1887, and became F.R.C.S. in 1893. At the London Hospital he passed through successive stages as surgical tutor, registrar, lecturer on ophthalmic surgery, and ophthalmic surgeon. He was for some years honorary ophthalmic specialist to the Military Hospitals of London, and chief clinical assistant at the Royal London Ophthalmic Hospital.

In 1916 he married Edith Annie, daughter of Dr. George Fletcher, who survives him.

\section{F. W. EDRIDGE-GreEN}

Mr. F. W. Edridge-Green, C.B.E., M.D., F.R.C.S., died on April 17, 1953, at the mature age of 89 . His name is well known to ophthalmologists throughout the world on account of his writings on colour vision and his invention of the colour perception spectrometer and the colour lantern, which are used to-day as tests for colour vision by many official bodies throughout the world. Fdridge-Green was a great controversialist with very decided opinions of his own, and although some of the conclusions he put forward seemed to lack a basis of observed facts, his name will be remembered as the first person to rationalize testing for colour blindness and to put it on a practical and generally acceptable basis.

\section{CORRIGENDUM}

Mr. H. B. Stallard apologizes for a mistake in the description of the Gillette blade in his paper on the "Technique of Lamellar Scleral Resection" published in the April number. This should read " $D$ " blade (not No. 15), the handle being No. 3 Gillette.

\section{FOR SALE}

Ophthalmometer (Zeiss): Test-types, Curry and Paxton three leaf model in oak frame, with striplite: Wall bracket light, Moorfields pattern: Electric ophthalmoscope, Keeler's wide-angle, continental model and transformer: Lister perimeter with adjustable table. 